\title{
App Inventor: ferramenta de autoria para a criação de aplicativos educacionais apropriados a crianças com Transtorno do Espectro Autista - TEA de Alto Funcionamento
}

\section{Evelin de Oliveira Haslinger ${ }^{1}$, Francisco Dutra dos Santos Junior ${ }^{1}$, Patrícia Fernanda da Silva ${ }^{1}$}

${ }^{1}$ CINTED/PPGIE - Programa de Pós-Graduação em Informática na Educação Universidade Federal do Rio Grande do Sul (UFRGS) - Caixa Postal 90.040- 060 Porto Alegre - RS - Brasil

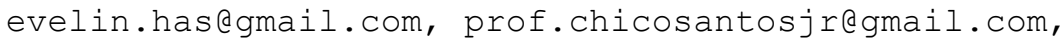

\begin{abstract}
This challenge arises as a consequence of studies and reflections on pedagogical practices with the use of "educational software for mobile devices". The possibilities of using this resource in the classroom may be favorable to the educator as a technology accessible to the inclusion of students with high-functioning autism spectrum disorder (ASD). Given this context, our goal is to develop a "QUIZ" for mobile devices - using the APPinventor app aimed at improving the social interactions of students with highfunctioning autism. Therefore, we believe that the application of a "QUIZ" with school daily expressions, may improve social interactions as well as communication, a common difficulty that ASD students presents.
\end{abstract}

Resumo. Este desafio nasce como consequência dos estudos e reflexões acerca de práticas pedagógicas com o uso de "software educacional para dispositivos móveis". As possibilidades da utilização deste recurso em sala de aula, pode ser favorecedora ao educador enquanto tecnologia acessivel à inclusão de educandos com TEA (Transtorno do Espectro Autista) de alta funcionamento. Diante deste contexto, nosso objetivo é desenvolver um "QUIZ" para dispositivos móveis - a partir do uso do aplicativo App Inventor voltado à melhoria das interações sociais de alunos com autismo de alto funcionamento. Portanto, acreditamos que a aplicação de um "QUIZ" com expressões do cotidiano escolar, poderá aprimorar as interações sociais, bem como da comunicação, tendo em vista a grande dificuldade que uma criança com TEA apresenta nesta área.

\section{Introdução}

De acordo com Garcia (2018), o App Inventor tem se mostrado uma "ferramenta gratuita de desenvolvimento mais apropriada para uso por professores sem formação em computação", uma vez que demonstra-se acessível para diferentes categorias de educadores, permitindo assim, "criar aplicações para mobile learning em qualquer área do conhecimento." 
Desta maneira, por que não criar um recurso mais atrativo para educandos com autismo de alta funcionalidade através da utilização do App Inventor? É, o que pretendemos mostrar a partir deste trabalho. Nosso objetivo é desenvolver um "QUIZ" para dispositivos móveis - a partir do uso do Aplicativo Inventor - para esses educandos. Esperamos assumir o desafio colocado e desenvolver futuramente o aplicativo com a participação de estudantes de uma escola municipal de Porto Alegre/RS especializada no atendimento de alunos com espectro autista e transtornos do desenvolvimento. $\mathrm{O}$ estudo está dividido em 4 capítulos. O capítulo 1 traz a introdução, em que apresentaremos os objetivos, justificativa e revisão de literatura. O segundo faz uma abordagem sobre o "App Inventor", dissertando sobre o software educacional escolhido para desenvolvimento do "QUIZ". No terceiro capítulo, "Autismo de alto funcionamento" focamos na discussão sobre a criança com TEA. E, por último, apresentamos os resultados esperados.

\section{App Inventor}

O App Inventor é um ambiente de autoria que permite programar por meio de blocos visuais. Através dele é possível criar aplicativos para smartphones e tablets que possuem o sistema operacional Android, atualmente aguarda-se o lançamento de uma versão também para iOS (Sistema Operacional da Apple Inc.). Embora seja uma ferramenta simples e de fácil exploração, ao utilizá-lo é necessário estar atento aos recursos que podem ser incorporados ao programa, pois pode haver dificuldades para usuários iniciantes, mas não para um educando com TEA de Alto Funcionamento.

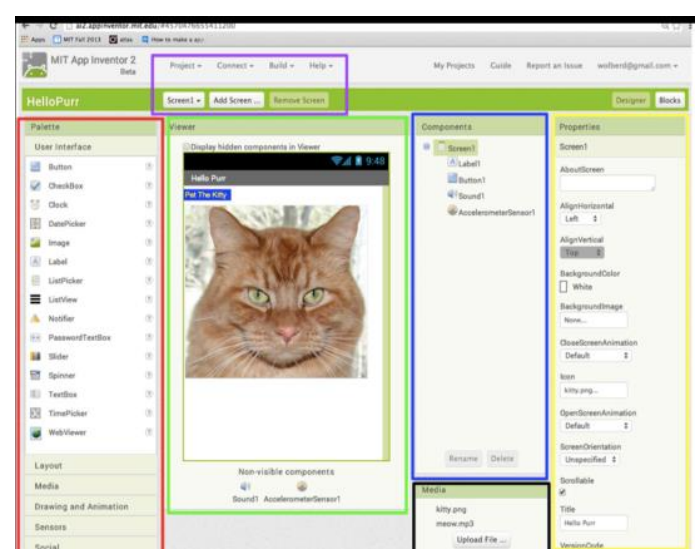

Figura 1. Designer view App Inventor

Para testar os aplicativos construídos, três modos distintos podem ser utilizados para a execução do programa: pelo Assistente AI, pelo Emulador e também pelo USB.

Ao utilizar a opção Assistente AI, um código em texto é gerado, juntamente com uma versão QR Code, por um programa que deve ser instalado previamente no smartphone. Ao ler o código um download do programa é realizado no aparelho, permitindo a exploração do mesmo.

$\mathrm{Na}$ opção por meio de emulador é necessário que um aplicativo seja executado previamente. $\mathrm{O}$ mesmo emula o ambiente de execução do aplicativo, o que possibilita 
testar o seu funcionamento. Outra opção é a conexão do smartphone por meio de cabo USB.

\section{Autismo de Alto Funcionamento}

Os vários grupos de autismo foram associados num único diagnóstico pela Associação Americana de Psiquiatria em 2013, passou-se a chamar de Transtorno do Espectro Autista-TEA. O Autismo de Alto Funcionamento até então era conhecido como Transtorno de Asperger. Pode apresentar algumas características como inteligência acima da média, habilidades visuais e espaciais, além de outros sinais que comprometem sua interação social, como raciocínio verbal inferior à média, comportamentos atípicos entre outros sinais de caráter adaptativo.

As manifestações comportamentais são aquelas que mais exigem alternativas de estratégias e recursos para que esses estudantes possam se desenvolver. Pelo seu alto funcionamento em áreas de funções cognitivas o interesse por recursos digitais passa a ser predominante nos diversos campos de interações com o meio.

\section{Resultados esperados}

Esperamos oferecer ao estudante com TEA melhoria no seu desenvolvimento e interações com seus colegas de escola, proporcionando assim uma inclusão mais efetiva.

\section{Referências}

García, Antonio Ortega, Ruiz-Martínez, Antonio e Valencia García, R. (2018). Using App Inventor for creating apps to support m-learning experiences: A case study. Computer Applications in Engineering Education.

Monteiro, Francisca Keyle de Freitas Vale, Dante, Augusto (2015) "Autismo e Tecnologia Assistiva: o autismo à luz da ciência para melhoria de vida das pessoas com Transtorno do Espectro Autista - TEA”, Engenho,São Luis.

Silva, Patrícia Fernanda da, Gheno, Giovani, Lammel, Iuri, TAROUCO, Liane Margarida Rockenbach "Formação de professores para desenvolvimento de software educacional". In: "V Conferência Ibérica de Inovação na Educação com TIC: ieTIC2019: atas da conferência", https://bibliotecadigital.ipb.pt/handle/10198/17747 .

Wolber, David et all "App inventor 2 - Create your own Android Apps". In: O’Reilly, Sebastopol-CA, 2015, http://www.appinventor.mit.edu. 